\title{
Introduction
}

\section{Political Radicalism Among the Younger Generations}

\author{
Anne Muxel \\ Senior Researcher, CEVIPOF (CNRS/SciencePo), Paris, France \\ anne.muxel@sciencespo.fr
}

In contemporary democracies, protest feeds on the difficulties currently facing political representation and is expressed within the framework of direct rather than representative democracy. The increase in protest-based attitudes and behaviours observed in many countries around the world (especially among younger generations) is undoubtedly related to the current climate of widespread mistrust in the institutionalized and representative mediation of politics. Since the beginning of the 1980s, a number of studies in political science have reported the gradual rise of more critical forms of citizenship to the detriment of institutional forms of civic and political participation. On the one hand, critical citizenship has gathered strength as the relationship between ordinary citizens and politics has become more individualised and, on the other, as traditional party allegiances have weakened (Hirschman, 1970, Inglehart, 1977, Norris, 1999). This more demanding and protest-based political culture, has led to greater familiarity with a protest-based repertoire of opinions and/or actions, and an enhanced tendency towards extremism and radicalization, particularly among younger generations.

The thresholds between legal and illegal forms of demonstration and/or collective mobilization are not easy to define. All research on what might be termed "civil disobedience" stresses the tenuous nature of the border zone in 
which the transition to radicalization takes place. Young people today become politicised in a climate where new connections between conventional and unconventional politics are manifold. The borders to radicalization have also become more porous, including at the voting polls. Protest voting and an inclination towards extremist parties is more prevalent among younger than older generations.

Violence is used as a subversive force and has an impact if not on the political system, at the very least on the social system. Some violent protest is explicitly based on political ideologies. However, new forms of violence have also emerged and have given rise to contrasting interpretations depending on whether they are labelled as political or not. For some, they stem from a logic of rebellion rather than from actual political issues in a context where "incivility" and deviance from the norm are on the rise. Others believe that, while they are outside the framework of institutionalized politics, they nonetheless originate in the actors' political conscience.

\section{A Set of Varied and Disparate Phenomena}

Political radicalism is not easy to define and expresses a set of varied and disparate phenomena which have in common protest and a categorical demand for profound change in society: denunciation of the established social order and the economic, cultural and political elites that support it, rejection of the institutions that underpin the political system in force, and a conviction that social and political structures should be radically transformed. Radical tendencies characterise both individual and group attitudes and behaviours, and build an entire repertoire of meanings and actions that are expressed in a broad variety of ways.

This special issue offers a comprehensive panorama of the large spectrum of these phenomena. Some contributions focus on opinions and ideology while others study peaceful protest. Some concentrate on explaining and discussing radicalism within the framework of democratic legitimacy while others address the issue of violence and illegality. While the intensity and sociopolitical consequences of radicalism may vary greatly, it is always based on the same notion of categorical rejection and refusal. Thus, radicalism opposes the conventional order of politics both in its principles and actions. It supposes profound contestation and a breaking-away from the established order. It legitimizes transgression up to the ultimate recourse to violence that it justifies. Finally, it feeds off the "extremisation" of ways of thinking about and interpreting the surrounding world. 
A distinction has to be made between on the one hand, cognitive parameters (attitudes and opinions) and on the other factors that lead to the act itself (behaviour) (Hafez, Mullins, 2015). Radical opinions are expressed as values and beliefs while radical acts entail taking concrete action within a legal context, for example, participating in a demonstration or joining a radical organization. However, radical acts may also take place in an illegal context, such as committing acts of violence, damaging public or private property, and possibly culminating in terrorism. While the links between these two dimensions are obvious, (and particularly the first as a precursor to the second), radical opinions are clearly far more widespread than radical acts. The vast majority of individuals with politically radical opinions or who adhere to radical belief systems, do not engage in any concrete form of action that aligns with these opinions. The contribution in this issue made by Philippe Shröder, who works on anti-Semitic attitudes among German adolescents, shows the relationships of such attitudes to ideological background, and above all to a right-wing political orientation. However, there is a clear gap between the opinions and the attraction to anti-Semitic attitudes adolescents may have and the anti-Semitic acts they might actually engage in. Only a minority of individuals engage in violent or subversive political action (Kurzman, 2011).

Thus, an individual or group with radical ideas will not necessarily adopt radical behaviour or engage in radicalized acts. The links and bridges between radical opinions and radical acts in the political field merit investigation, particularly to determine whether one and the other follow the same logic, and more particularly, whether they have the same intentions. It is essential to define the threshold of opinion or action beyond which politicization can be defined as radical or radicalized.

Many authors have stressed the difficulty of delineating the perimeters of political radicalism and a number have written about the nebulous web of types of radicalism. Between the two ends of a political radicalism scale, a huge diversity of types of expression and intermediary political activities can be perceived. At one end of the scale, non-mainstream political parties adopt electoral strategies that promote anti-system protest programmes and radical attitudes. At the other end of the scale, the logic of violent or terrorist acts predominates. The thresholds between these different degrees of radicalism are not always clearly identifiable. Political analysts frequently disagree on what exactly does or does not constitute radicalism. Some believe that this diversity of definitions should be analysed as part of a continuum that supposes a gradual and coherent process of radicalisation among both individuals and groups, while others believe such diversity should be interpreted as highlighting the absence of connection between the different phenomena of political 
radicalism observed. The first approach, initiated by Charles Tilly, tends to consider radicalism as a series of phenomena that are not only coherent but also gradual, and part of the same dynamic of political meaning and action (Tilly, 1978). Radicalism then becomes a question of degree and intensity along the same continuum that stretches from potential engagement to a culmination in revolutionary violence. Thus, the research carried out by Doug McAdam on US activists in the 1970s-1980s, led to a now classic interpretation of political radicalism in terms of degree or intensity, that distinguished between low and high cost, and low and high risk activism (McAdam, 1986). The second approach sees radicalism through a prism that not only differentiates between radical opinions and acts but also shows certain acts as being exceptional events. Violence, for example, is considered as an expression of radicalism that is outside the norm and that follows a "tipping-point" or conversion (Della Porta, 1995), or that is part of an individual or collective pathology.

However, the thresholds between the two and the borders surrounding the grey areas of radicalism are not easy to define. On this point, Alan Marsh's well-known diagram (1977) lists the different forms of political participation citizens are likely to engage in, depending on whether they are considered to be "orthodox and conventional" or "unorthodox and unconventional". The diagram also reveals the tremendous complexity involved in identifying possible areas of overlap between the two. For example, the radicalism threshold between a legal and an illegal demonstration is not easy to define, nor is the occupation of a given premises or the blockading of a factory in comparison with a violent act. All research on what might be qualified as "civil disobedience" stresses the tenuous nature of the border between civil disobedience and radicalism and between radicalism and violence. In their contribution to this issue, Sarah Pickard and her co-authors, discuss the change of "radical repertoires of contention" in the specific case of environmental mobilisation led by Extinction Rebellion. Young environmentalists represent a generation of activists who express radical demands in order to obtain significant change, given that they cannot operate within the bounds of existing systems. Nevertheless, their actions are deliberately non-violent and "radical in our kindness" to use the words of by a young protestor.

The broadened and diversified spectrum of radicalism makes it possible to include a wide range of political phenomena related to protest, including in the context of conventional politics, in how it is defined. Thus, protest votes for non-mainstream parties, either on the Left or the Right, indicate an element of radicalism. Certain forms of populism provide an outlet for such political radicalism, notably by denouncing the political system, its elites and its institutions, and by creating a space for protest and radicalism in the name 
of sovereignty for the people. Similarly, collective mobilization and street demonstrations are used to protest against government policies, demand social change, fight against discrimination and inequality, or call for the recognition of minority rights. They provide opportunities for radical opinions and acts to be aired or executed through what Alain Touraine has described as "new social movements" in post-industrial societies (Touraine, 1969). These protean movements, which may or may not be structured, convey a whole series of reactions and protests by civil society towards the State, capitalism and economic liberalism. They also demand recognition of the rights of minorities and support the causes of people in precarious situations on the margins of society, otherwise known as the "sans" (i.e. those who do without and/or who are excluded) (Kriesi et al, 1995). In line with the demand for various identities to be recognised and affirmed, the theme of discrimination has partly replaced the theme of inequality. These new identity-based issues can potentially lead to radical ways of thinking and doing. Last but by no means least, the current increase in environmental mobilisation (the majority of which is carried out by young people) has introduced a significant protest repertoire that is driving profound changes in society and, in that sense, is potentially radical to the political landscape of many countries. The two contributions made by Sarah Pickard et al. and Maxime Gaborit to this special issue stress this new environmental framework and the prevalence of the climate issues at stake that are redefining the politicisation of younger generations today.

Thus, the space for political radicalism appears to be readily available. It includes a whole series of phenomena proper to "ordinary" and passive radicalism, in contrast to other phenomena proper to extremist and violent radicalism.

\section{Are Younger Generations More Radical? Delineating Protest and Violence}

Radicalism has different implications depending on whether it is "radicalism through protest" which can be defined as a desire for change from inside the system that does not include committing or justifying acts of violence or "radicalism through violence" which supposes a desire for change from outside the system that includes justifying and/or committing acts of violence.

The first of these is prevalent among a broad cross-section of young people, and may herald a new norm of politicisation. In terms of the diversity of ways in which it is expressed together with its political consequences, this type of widespread protest may or may not be radical. Nevertheless, it brings 
together a repertoire of ideas and acts that result in a type of contestation that takes place outside the workings of political representation and conventional involvement, and in that sense can be defined as radical. Félix Krawatzek's contribution to this special issue shows how young Russians perceive protest in authoritarian regimes, depoliticise their demands and do not seek obvious political change. He explains this low interest in radical politics in Russia by the fact that younger generations are fragmented within Russian society and are also deeply disillusioned. This very low level of interest in radical mobilisation reflects the power of the Poutine regime to determine what is considered as appropriate civic activism. Nevertheless, his survey also shows that despite the regime's relative coercion, young Russians are more and more likely to view protest as legitimate. There is a hiatus between their democratic way of thinking and their reluctance to become politically involved. This hiatus may strengthen their submission to the authoritarian and populist regime, but ultimately, it may also promote movements fuelled by a variety of demands and a call for emancipation. In their article on the contrary, Sarah Pickard et al. show the determination of the young Extinction Rebellion activists to change society, adopting radical ideas and demanding urgent reforms and reorientations for the environment.

The second type of radicalism supposes subversive attitudes and behaviours and is characteristic of an outright rejection of the system itself rather than merely protest. Most notably, it does not exclude the commitment of violent acts. Although extremism and violence are linked to a high potential for radicalism, they do not necessarily overlap on a scale of radical attitudes and behaviour. Whether a violent act is interpreted as part of a continuum or as part of a dissociated logic, it remains exceptional. This is because in the repertoire of individual or collective action, it is defined as an ultimate recourse. It is therefore a rare occurrence even when justified and legitimized by those who perpetrate it. Here too, definitions of political violence in the specialized literature are controversial. Although violence expresses itself in different ways, the definition provided by HL Nieburg (1969, p.13) is useful for our purposes: "acts of disruption, destruction, injury whose purpose, choice of targets or victims, circumstances, implementation and/or effects have political significance, that is, tend to modify the behavior of others in a bargaining situation, that has consequences for the social system").

Many authors have highlighted a number of changes in political violence in recent times. While the 1970 s were marked by forms of violent activism explicitly drawn from political ideologies (some of which were spread by very small groups), new repertoires of violence have emerged since then, particularly among the young, as for example in the case of urban riots in France. Such 
violence has given rise to contrasting interpretations depending on whether they are labelled as political or not. For some, they are not motivated by political issues in the strict sense, but rather by a desire for rebellion, in the context of a rise in "incivility" and deviant behaviour, as well as a demand for recognition. Others agree on the proto-political dimension, external to the framework of institutional politics, but which clearly stems from the political consciousness of those who resort to violence. Wherever the truth may lie, these changes define a type of radicalism where violence is used as a force of subversion that will have an impact, if not on the political system, at the very least on the social system. In his contribution to this issue, Maxime Gaborit having interviewed young environmental activists during recent protest actions shows the strong divisions that exist among them regarding their propensity to commit some acts of violence or to justify them as the only way to be heard. The consciousness of the urgency of the climate situation opens the way for the acceptance of more radical actions.

In political terms, radicalism implies adhering to ideas or behaviours that suppose an opposition the ordinary game of politics and political institutions, together with an overt anti-system protest strategy, ranging from protest to violence. These different types of contestation are expressed at election time (voting for an extremist party, protest through abstention), or in the streets (demonstrations, collective mobilisation, strikes). Although violence is one component of political radicalism, it does not feature systematically. Violence includes deliberate physical attacks on goods and/or people and are sometimes the result of emotional eruptions during infra- or proto-political spontaneous events (riots). Violence may also be part of a political strategy designed to bring about radical change in society and the breakdown of its institutions (revolution, terrorism). Thus, political radicalism is characterised by multi-faceted dispositions, forms of expression and action whose interpretation depends on the socio-historical and political context within which it is analysed.

The contribution made by Confidence Chia Ngam in this issue is focused on an extreme form of radicalism in the context of civil war in Cameroon. She studies radicalization and recruitment into the Anglophone Separatist Militia engaged in armed confrontation replete with various forms of violence. For this Militia, violence and war are considered as the only option to resurrect a nation corresponding to the Southern British-administered Cameroon. The Amba Boys are very young, most of them are criminals and school dropouts, brainwashed and drugged, full of acrimony and disgruntlement against the Cameroon political leadership who have neglected the aspirations of people of the English-speaking regions since 1961. Overwhelmed by high and willing spirits, using fetishes as ancestral beliefs and incarnation hooded in the bosom 
of African traditional religion, the Amba boys are ready to fight and to commit crimes. Radicalism expressed with an extreme violence mobilizes mixed references, using a large spectrum of means, modern (social media) and traditional (tribal and traditional religion).

Apart from this specific case of extreme violence, in a very particular historical and political context, a sizable amount of radicalism is present within western democracies among the population as a whole and, more especially, among younger generations. At times, such radicalism - particularly radicalism through protest - remains within the democratic framework to a greater or lesser extent and seeks solutions to the failings in the system from within. At times, radicalism becomes extreme - radicalism through violence - and turns to outright opposition to the democratic system by means of the violence it fuels and as a result of its disdain for democratic pluralism.

By its very nature, youth is oriented towards change. In a quasi-structural manner, this is the age when anything and everything is possible, a period in life where visions of changing the world around them - visions that may or may not be radical, that may or not be utopic - resonate strongly. In their article, Sarah Pickard et al. stress the climate emergency that young Extinction Rebellion activists draw attention to: "Change now" is their leit-motiv and the basis for radical attitudes and radical ecological solutions they promote. The attraction of the new and of renewal is strong. And for many, the desire to change things defines a horizon of expectations that may eventually find a political outlet.

\subsection{Protest Due to a More Widespread Critical Citizenship}

Since the beginning of the 198 os, political science research has documented the gradual rise of a more critical citizenship to the detriment of institutional civic and political engagement and classical democratic participation, notably through the vote and partisan activism. For some political scientists, following the work of Pippa Norris (1999) on critical citizens, the idea of "protest democracy" (Mathieu, 2011) or more radically of "insurgent democracy" (Abensour, 2009) that is reconfiguring the very foundations of representative democracy has taken root. The relationship to politics has become more individualised and traditional partisan allegiances have declined. Taken as a whole, these changes have profoundly modified the relationship between citizens and the public arena. A political protest culture has become more generalised, legitimised 
and, in a certain sense, more demanding. In this context, the potential for radicalism or at any rate for a greater familiarity with its repertoire of attitudes and acts, notably among younger generations has greatly expanded (Muxel, 2019).

Abstention also plays a unique role in the expression of protest. Today, the idea of the vote as a civic duty has significantly weakened and analysis of electoral behaviour shows an increase in the use of intermittent voting and abstention. A certain level of civic fatigue, particularly as a result of generational change together with a rise in the use of abstention as political protest have regularly been observed. In recent times, the spoiled or blank vote and the calls for recognition such a vote gives voice to, has become more widespread as a means to express citizen protest. All these behaviours are part of what Pierre Rosanvallon (2006) has called a "counter-democracy", where the legitimacy of democratic representation itself is contested, and ever more frequently, the electoral majority principle which forms the basis for its legitimacy. These critical tendencies do not only concern longstanding Western democracies. In this issue, Félix Krawatzek's paper provides an example of the increasing legitimacy of protest in Russia for instance, even among young people who are not interested in politics and who are not inclined to participate, and despite a context where authoritarian leadership is predominant and not much rejected. From protest expressed at the ballot box to radicalism in the street, substantial changes in citizen political practices are becoming more apparent. Collective forms of mobilisation as diverse as flash mobs, gatherings organised through internet, boycotts, mediatised happenings and videos posted on social networks, are used to express a multitude of actions and "acts of citizenship" (Isin and Nielsen, 2008), and have created an entire civic grammar that includes the radical dimension of what political action is understood to be.

Young people today enter the political arena in a profoundly changed context: the crisis in attitudes towards political parties and partisan identification, the blurred lines of the Right-Left cleavage, the diminished civic norm of the duty to vote and the increase in abstention, and the heightened legitimacy of a protest culture that has become commonplace, are all phenomena observed by political sociologists in a number of Western democracies. The political and civic socialisation of younger generations takes place in this particular climate where the workings and the principles of representative democracy are constantly being called into question. As a result, more critical forms of politicisation, often containing an element of radicalism, are emerging. Direct expression, protest, and ever more frequently, forms of engagement that contrast with more conventional involvement have multiplied. However, while such distrust in politics can lead to active and open criticism, it can also remain silent and fuel indifference. It can favour the search for new types of expression and mobilisation but it can also foster detachment. This detachment 
could lead future citizens to adopt a "radical" posture of self-exclusion from the social and political system. This is also a risk that modern democracies have to face.

\subsection{Individual and Psychological Factors}

Adolescence is a pivotal period in the building of an identity and notably a political identity. A large amount of research in clinical and political psychology has shown the importance of idealism and, in particular, processes of identification with collective ideals, self-esteem and the development of a personal autonomous psyche (Kestemberg, 1962). Added to this, the period can be considered to be exemplary of the quest for idealisation.

Research on radicalism have shown that radical attitudes do not seem to result from socio-economic factors linked to the social background of the young people concerned alone. Socialisation at school and political socialisation within the family have a greater impact as do complex contextual variations linked both to gender and to subjective parameters such as the perception by a young person that they have experienced discrimination. Contextual, collective and individual factors, must also be taken into account.

The propensity to support extreme ideologies and the violence they may lead to, has often been seen as the sign of pathological personality traits (Reich, 1969, Fromm, 1973), or of an authoritarian personality (Adorno et al., 1950, Eysenck, 1954). Other approaches, such as Marxism, have argued that economic factors and social conditions that foster a sense of cultural, social and intellectual isolation among certain sections of society together with a whole series of frustrations and resentments, favour the development of radicalism (Gurr, 1970). As the ideological landscape evolved, it did appear at one point that these extreme ideologies were becoming more and more marginalized over time. However, analysis of the current political and social reality, and in particular the return of violent religious radicalism in recent times, demonstrates their resistance, the resurgence and indeed the emergence of new modes of extremist thinking, as evidenced by the Islamist fundamentalism underlying jihad.

Recent approaches to radicalism and the phenomena of radicalization agree on the plurality of explanatory factors and the difficulty of untangling them. Such approaches show a "jigsaw puzzle" of diverse causalities that include: socio-economic and psychological factors, the conditions of familial socialization, the role of secondary socialization, the influence of the political context and the organizational and institutional environment, and the influence of the media (Hafez, Mullins, 2015). Many also agree that in order to express itself, radicalism (whether it be of a cognitive nature or translated into behaviour or action) goes hand-in-hand with the ability to "believe" and 
to "convince" (Muxel, 2017). Radical political commitment entails fighting for a cause and defending ideas that the individual believes in. However, the first step in understanding the mechanisms of "believing", is to understand how and in what circumstances adherence to radical ideas takes root.

The main paradigmatic grids for the analysis of political engagement are useful here: the sociological explanation that prioritises the social and cultural background of individuals and privileges theories of alienation and social domination; the psychological and psycho-social explanation where questions of identity or phenomena connected to "relative frustration" prevail (well analysed by Ted Gurr (1970)); economic and rational approaches, as in Olson's perspective (1965) that highlights notions of the costs, risks or rewards of activism; the resource model that takes contextual factors at the micro-level (individuals), meso-level (organizations) and macro-level (institutions and rules) into account (Weldon 2008, Morales, 2009). The question of rationality versus political passion is also quite widely discussed in research, notably with respect to terrorism, with such discussion clearly showing that separating one from the other is not an easy task. Taken as a whole, these interpretational grids make it possible to identify a certain number of phenomena at work in how political radicalism is expressed.

Violence primarily concerns males rather than females. While there is no significant gender-based difference for radicalism through protest, radicalism through violence is clearly connected to the notion of and quest for virility, which is confirmed by research carried out on the phenomena of violence among young people. Nevertheless, recent research shows that while women are less likely to favour violence and extremism, they nonetheless do so to some extent.

Frustration, feelings of injustice, and a gap between individual expectations and the reality of conditions encountered, are well-documented factors in the transition to violence. The former are personally felt frustrations, which means that subjective processes associated with radicalism must also be taken into consideration. Radical tendencies may be part of a quest for meaning and benchmarks to help the individual deal with loss of meaning in a world in transition. Radicalism can also be the result of boredom and indifference (Van Tilburg, Igout, 2016). It is sometimes subliminally imagined as the route to an ideal of society that compensates for disillusionment with real life (Mc Gregor, Prentice, Nash, 2013). In this sense, radicalism can be experienced and embraced as a kind of day-dream (Roger Griffin, 2003) taking place in an "atemporal" eternal domain that makes up for the alienation the individual has experienced in the necessarily limited time of ordinary life. It can also be a means to reduce uncertainty and anxiety, through its quest for a homogeneous world and a reassuring political consensus (Onnudottir, Porisdottir, 2015). 
As an example of extreme radicalism in this issue, Confidence Chia Ngam shows how convinced the Amba Boys in Cameroon are that violence is the only way to achieve the independence for which they are fighting. Violence and war are considered as an option for nation-building. Political opportunities also have an impact on the way radical movement can interact. Leanne Serbulo's article presents the case of the far-right/anti-fascist protest cycle in Portland in the United States. She has studied the mechanisms of radicalization and de-radicalization operating when two violent protest movements interact with state security forces. If the respective extreme ideology of the two movements is indeed a pretext for activists to fight each other, the adoption of violence is socially emergent rather than ideologically-driven. Developing a relational approach, Serbulo shows the importance of tactics produced as activists interact with oppositional forces, and also the specific role of the police repression that is not neutral. Rather than deescalating the situation, underbidding by the police led to an increase in movement/counter-movement violence.

The search for an in-group to identify with is an important element of juvenile sociability and the building of an identity during adolescence. In his article, Felix Krawatzek highlights the importance of peers and of friendship networks to explain not only the disposition of young Russians to participate and to protest, but also their understanding of the legitimacy of protest. Interpersonal relationships are decisive in the process of political socialization of individuals, even in its most radical aspects.

Sharing the same beliefs and designating common enemies by shunning surrounding out-groups is also a significant factor in adherence to radical beliefs (Sustein, 2009), as are extremist radical attitudes including intolerance and hostility towards difference (Van Prooijen, Krouwel, 2017). In measuring anti-Semitic attitudes among young Germans in this special issue, Philip Shroeder confirms the particular vulnerability of adolescents to radicalization processes. A sense of discrimination can also fuel conflictive otherness and give rise to radical opinions and behaviours that serve as an outlet for the malaise felt. Radicalism can then become a demand for social and political recognition, a default resource and a means to make oneself visible and heard.

This special issue of Youth and Globalization compiles empirical studies on the expanding protest and potentially radical framework for political involvement among younger generations. It provides a number of clues to better understand the mechanisms that are involved - individually and collectively - in producing radical attitudes and actions. The cases presented involve different countries and different cultures. The causes of and motivations for radical attitudes and action presented and discussed in this special issue are diverse, and, at times, are in complete opposition to each 
other. Nevertheless, what all these contributions have in common is that they inform on what political radicalism implies and means. They also outline the relationships young people entertain with the political system and the society they belong to, where by definition, they need to find a place for themselves.

\section{References}

Abensour, M. 20og. “'Démocratie Insurgeante' et Institution." In La démocratie au-delà du Libéralisme. Perspectives Critiques, edited by Breaugh M. and Dupuis-Déri F., 185-193, Outremont: Athena Editions, « Chaire mcd».

Adorno, T. W., E. Frenkel-Brunswick, D. Levinson, N. Sandford. 1950. The Authoritarian Personality. New York: Harper Book [réédité New York, W.W Norton \&Co, 1969].

Della Porta, D. 1995. Social Movements, Political Violence and the State. Cambridge: Cambridge University Press.

Eysenck, H. J. 1954. The Psychology of Politics. London: Routledge.

Fromm, E. 1973. The Anatomy of Human Destructiveness. New-York: Holt, Rinehart and Winston.

Griffin, R. 2003. "Shattering Crystals: the Role of 'Dream Time' in Extreme-Wing Right Political Violence." Terrorism and Political Violence 15(1): 57-95.

Gurr, T. R. 1970. Why Men Rebel? London: Routledge.

Hafez, M., C. Mullins. 2015. "The Radicalization Puzzle: A Theoretical Synthesis of Empirical Approaches to Homegrown Extremism." Studies in Conflict and Terrorism 38: 958-975.

Hirschman, A. O. 1970. Exit, Voice and Loyalty. Responses to Decline in Firms, Organizations and States. Cambridge: Harvard University Press.

Inglehart, R. 1977. The Silent Revolution, Changing Values and Politics Styles Among Western Publics. Princeton: Princeton University Press.

Isin E. F., G.M. Nielsen (eds). 2008. Acts of Citizenship. Chicago: Chicago University Press.

Kestemberg, E. 1962. "Lidentité et l'Identification chez les Adolescents. Problèmes Théoriques et Techniques." La Psychiatrie de l'Enfant 5(2): 441-422.

Kriesi, H. P., R. Koopmans, J.W. Duyvendak, M. G. Giugni, 1995. New Social Movements in Western Europe: a Comparative Analysis. London: University of Minnesota Press.

Kurzman, C. 2011. The Missing Martyrs: Why There Are So Few Muslim Terrorists. New York: New York University Press.

Marsh, A. 1977. Protest and Political Consciousness. Beverly Hills: Sage.

Mathieu, L. 2011. La Démocratie Protestataire. Mouvements Sociaux et Politiques en France Aujourd'hui. Paris: Presses de Sciences Po. 
McAdam, D. 1986. "Recruitment to High-Risk Activism. The case of Freedom Summer." American Journal of Sociology 92(1): 64-9o.

McGregor, I., Prentice, M., Nash, K. 2013. "Anxious Uncertainty and Reactive Approach Motivation (RAM) for Religious, Idealistic, and Lifetime Extremes", Journal of Social Issues, 69, p.537-563.

Morales, L. 2009. Joining Political Organizations. Colchester: ecpr Press Monographs.

Muxel, A. (ed.). 2017. Croire et Faire Croire. Des Usages Politiques de la Croyance. Paris: Presses de Sciences Po.

Muxel, A. 2019. "Youth and Politics in France: Democratic Deficit or New Model of Citizenship." In The Routledge Handbook of French Politics and Culture, edited by Demossier M., Lees D., Mondon A., Parish N., London, Routledge.

Nieburg, H. L. 1969. Political Violence, The Behavioral Process. New-York: St Martin's Press.

Norris, P. 1999. Critical Citizen, Global Support for Democratic Governance. Oxford: Oxford University Press.

Olson, M. 1965. The Logic of Collective Action, Cambridge: Harvard University Press.

Onnudottir, E. H., H. Porisdottir. 2015. "Need For Security and System Fairness on the Political Extremes." Icelandic Review of Politics and Administration 11(2): 115-138.

Reich, W. Psychologie de masse du fascisme (1969), trad. fr. Kamnitzer P., Paris, Payot, 1972.

Rosanvallon, P. 2006. La Contre-Démocratie. La Politique à l'Age de la Défiance. Paris: Editions du Seuil.

Sustein, C. R. 20o9. Going to Extremes: How Like Minds Unite and Divide. Oxford: Oxford University Press.

Tilly, C. 1978. From Mobilization to Revolution. Reading, MA: Addison-Wesley Publishing Co.

Touraine, A. 1969. La Société Post-Industrielle. Paris: Denoël.

Van Prooijen, J. W., A. P. M. Krouwel. 2017. "Extreme Political Beliefs Predict Dogmatic Intolerance." Social Psychological and Personality Science 8(3): 292-300.

Van Tilburg, W. A. P., E. R. Igout. 2016. "Going to Political Extremes in Response to Boredom." European Journal of Social Psychology 46(6): 687-699.

Weldon, L. 2008. "Intersectionnality." In Politics, Gender and Concepts. Theory and Methodology, edited by Goertz G. and Mazur A. G., 193-218. Cambridge: Cambridge University Press. 